\title{
Determinants of Preferences for Advertisement and Communication in the Promotion of Anti-Malaria Products in Ibadan, Southwestern Nigeria \\ DOI: $10.36108 / \mathrm{NJSA} / 6102 / 14(0220)$
}

\author{
Kabiru K. Salami* \\ Chinwe M. Onuegbu \\ Department of Sociology \\ University of Ibadan \\ Ibadan, Nigeria
}

*Corresponding Author: kabsalami@yahoo.co.uk

\begin{abstract}
One of the strategies for promoting malaria prevention and control globally is advertisement of anti-malaria products. This study was designed to determine users' preferences for style of advertisement and communication of anti-malaria products in Ibadan. Data collection involved twelve Key Informant Interviews and 500 copies of a questionnaire. Radio was the most preferred and most accessible medium of advert in both rural and urban areas. A large majority (86.4\%) of rural dwellers preferred advertisements in form of speeches, house-to-house campaigns, face-to-face counselling and rallies. Whereas, advertisement in forms of drama (44.0\%) and music (16.0\%) were preferred by the urban dwellers. Results show that advertisements and communication programs on anti-malaria products do not relay messages on drug reaction and its treatment, and cost of anti-malaria products. Hence, advertisements and communicative programmes for controlling malaria would be more effective if the social and environmental factors influencing preferences for advertisement are put into consideration.
\end{abstract}

Keywords: Media, health communication, health promotion, malaria prevention, Nigeria

\section{Background}

Malaria as an endemic disease has continued to pose a major threat to the health of people in Nigeria. It accounts for a high rate of morbidity and mortality in the country (Nigeria Malaria Fact Sheet, 2011) with approximately $50 \%$ of the population suffering at least one episode of malaria each year (National Malaria Indicator survey, 2010). Malaria also creates a burden, not only on the welfare of households but also on the level of productivity, investment and economic wellbeing of a nation (Usman and Adebayo, 2011). As malaria is both preventable and treatable, the World Health Organization (WHO) recommends the use of Long Lasting Insecticide Treated Nets, Insecticides for vector control and Artemisinin-based Combination Therapy (ACT) for treatment of malaria. These, alongside environmental sanitation, promote the goal of combating malaria in sub-Saharan Africa where the disease is predominant (WHO, 2010). While most anti-malaria tools are 
available in Nigeria through the joint efforts of pharmaceutical companies, the Federal Government and foreign donors, accessibility to these tools, especially regarding the information about their sources and promotion of their usefulness, is communicated to the public through various media.

Advertisements and sensitisation campaigns on malaria have also become regular features of media messages daily. The Roll Back Malaria (2012) noted that well-planned and executed communication programmes contribute to achieving malaria prevention and treatment in a wide range of ways. Reports from the Nigeria Malaria Indicator Survey (NMIS, 2012) established how pertinent it is to pass adequate information and ensure that educational materials get to both rural and urban population. The observation by Oladepo, Tona, Oshiname and Titiloye (2010) on dearth of knowledge and/or inadequate awareness concerning appropriate treatment or preventive practices against malaria creates concerns on the need for production of proper advertisement and communication strategies in the promotion of anti-malaria treatment and prevention. It is true that socio-cultural factors, environmental issues and differences in socio-economic status have influence on advertisement and communication preferences of rural and urban dwellers. Advertisement and communication strategies must take cognisance of the social environment and different life chances of target audiences (Salami and Onuegbu, 2016). Dramas, jingles, pictures, and song-relaying messages on malaria (Luyiga, 2013) often disseminated through radio, television, the internet, and billboards (among others) could be important strategies for controlling the disease. However, their strength may be limited by the way the messages are perceived by the people. This study examines the advertisement and communication preferences of the rural and urban dwellers pertaining to prevention and treatment of malaria in Ibadan, Nigeria.

\section{Methodology}

This descriptive cross-sectional study was carried out among care-givers in each of the communities in Egbeda Local Government Area (rural) and Ibadan North Local Government Area (urban) in Ibadan, Nigeria. The target population for this study comprised 500 caregivers and twelve patent medicine vendors. A multi-stage sampling technique was adopted, beginning with the purposive sampling/selection of one rural local government area (LGA) and one urban LGA in Ibadan. The second stage involved simple random selection of two (2) wards each out of the two LGAs initially selected; Egbeda LGA and Ibadan North LGA. In Egbeda LGA comprising 11 wards, Awaye and Egbeda were selected, while in Ibadan North LGA which is divided into 12 wards, Bodija and Mokola were selected. Hence, a total of four (4) wards were selected for this research. Finally at the wards selected for this study, efforts were made to locate respondents by visiting them in their homes. In the homes that the researchers visited, respondents were briefed on the background of the study and their consent to participate in the study was sought. Therefore, participation was voluntary. On daily basis all questionnaire copies were 
edited. Edited copies of the questionnaire were duly coded and analysed using SPSS to prepare descriptive statistics for the quantitative data, while content analysis was used in analysing qualitative data.

\section{Results}

Table 1 reveals that more than half $(57 \%)$ of the respondents are male. Respondents' ages range between 16-25 years (11\%) and 66+ years $(1.4 \%)$. The analysis of educational qualification of the respondents shows that $35.2 \%$ had SSCE, about $16.0 \%$ have primary school education while $14.0 \%$ have no formal education. A large majority $(80.8 \%)$ of the respondents are married as against $15.8 \%$ that are single. The majority $(77.8 \%)$ of the respondents belong to Yoruba ethnic group; $12.0 \%$ from Igbo ethnic group; $1.4 \%$ from Hausa ethnic group and others $(8.8 \%)$ such as Tiv or people from Cotonou are also involved. Data on religious affiliation of the respondents show that $58.0 \%$ are Christians, $36.0 \%$ are Muslims, while $4.0 \%$ are traditional religious worshippers. In term of household structure, the large majority $(82.4 \%)$ of the respondents are from nuclear families than from extended families $(16 \%)$.

Table 1: Socio-Demographic Characteristics of the Respondents

\begin{tabular}{|l|l|l|l|}
\hline Variable & Frequency (N=500) & Percentage \\
\hline Sex & Male & 285 & 57.0 \\
& Female & 215 & 43.0 \\
\hline Age & $16-25$ & 57 & 11.4 \\
& $26-35$ & 108 & 21.6 \\
& $36-45$ & 141 & 28.2 \\
& $46-55$ & 132 & 26.4 \\
& $56-65$ & 53 & 10.6 \\
& $66-75$ & 3 & 0.6 \\
& $76-85$ & 4 & 0.8 \\
& No response & 4 & 0.8 \\
\hline Educational status & No formal education & 70 & 14.0 \\
& Primary & 81 & 16.2 \\
& JSSE & 28 & 5.6 \\
& SSCE & 176 & 35.2 \\
& OND & 24 & 4.8 \\
& HND & 63 & 12.6 \\
& B.Sc & 20 & 4.0 \\
& M.Sc, Ph.D & 26 & 5.2 \\
& No response & 12 & 2.4 \\
\hline Marital status & Single & 79 & 15.8 \\
& Married & 404 & 80.8 \\
& Divorced & 2 & 0.4 \\
& Widowed & 15 & 3.0 \\
\hline
\end{tabular}




\begin{tabular}{|l|l|l|l|}
\hline Ethnic group & Igbo & 59 & 11.8 \\
& Yoruba & 389 & 77.8 \\
& Hausa & 7 & 1.4 \\
& Tiv, Cotonou & 44 & 8.8 \\
& No response & 1 & 0.2 \\
\hline Religion & Christianity & 290 & 58.0 \\
& Islam & 180 & 36.0 \\
& Traditional worship & 20 & 4.0 \\
& No response & 10 & 2.0 \\
\hline Household & Nuclear & 412 & 82.4 \\
structure & Extended & 78 & 15.6 \\
& No response & 10 & 2.0 \\
\hline
\end{tabular}

More than half $(58.0 \%)$ of the rural dwellers live in their family houses than their counterparts in urban $(3.6 \%)$ locations. The urban dwellers $(66.0 \%)$ reside mostly in rented apartments. Most urban and rural dwellers possess radio and mobile phones. Electricity supply is recorded to be between 1-6 hours daily while very few respondents get electricity supply up to between 13-18 hours. The study also documented possession of indices for measuring health outcome at household level. Majority $(n=339)$ of the respondents reportedly source their water from "well" (rural: $187=74.8 \%$, urban: $152=60.8 \%$ ). Water is stored in closed containers in rural $(\mathrm{n}=203)$ and urban $(\mathrm{n}=58)$ areas; and in clay pots $(12.0 \%)$ each for rural and urban locations as shown in table 2 . The respondents also provided information on their means for water disposal. More rural dwellers $(51.8 \%)$ dispose water in open gutters, followed by $44.0 \%$ who use open grounds, while very few $(4.0 \%)$ indicate that they dispose their unclean water via sewage system. In the urban area, a large majority $(72.8 \%)$ of the respondents utilise open gutter; about $20.0 \%$ dispose unclean water via sewage system, while only $7.6 \%$ dispose unclean water on open grounds within their premises. Most rural (40.0\%) and urban (51.2\%) dwellers sanitise their drainage systems on a weekly basis, while $13.0 \%$ of rural dwellers and $8 \%$ of urban dwellers do not sanitise their drainages at all. Respondents in rural community reportedly dump their refuse at their backyards $(52.0 \%)$, public grounds $(40.0 \%)$ and in public incinerators $(8.0 \%)$. Urban dwellers use covered bins $(33.2 \%)$, refuse collectors $(31.2 \%)$, backyards $(28.0 \%)$ and public ground $(7.6 \%)$. 
Table 2: Respondents' Possession of Health Outcome Indices

\begin{tabular}{|c|c|c|c|c|c|}
\hline \multicolumn{2}{|c|}{ Health outcome indices } & \multicolumn{2}{|l|}{ Rural area } & \multicolumn{2}{|l|}{ Urban area } \\
\hline $\begin{array}{l}\text { House } \\
\text { Ownership }\end{array}$ & $\begin{array}{l}\text { Personal house } \\
\text { Rented house } \\
\text { Family house } \\
\text { Staff Quarters }\end{array}$ & $\begin{array}{l}\begin{array}{l}\text { Frequency } \\
(\mathbf{N}=\mathbf{2 5 0})\end{array} \\
63 \\
40 \\
145 \\
2\end{array}$ & $\begin{array}{l}\begin{array}{l}\text { Percen- } \\
\text { tage }\end{array} \\
25.2 \\
16.0 \\
58.0 \\
0.8\end{array}$ & $\begin{array}{l}\begin{array}{l}\text { Frequency } \\
(\mathbf{N}=\mathbf{2 5 0})\end{array} \\
66 \\
165 \\
9 \\
10\end{array}$ & $\begin{array}{l}\begin{array}{l}\text { Percen- } \\
\text { tage }\end{array} \\
26.4 \\
66.0 \\
3.6 \\
4.0\end{array}$ \\
\hline $\begin{array}{l}\text { Sources of } \\
\text { water supply }\end{array}$ & $\begin{array}{l}\text { Tap } \\
\text { Well } \\
\text { Borehole } \\
\text { Tanker trucks }\end{array}$ & $\begin{array}{l}51 \\
187 \\
2 \\
10\end{array}$ & $\begin{array}{l}20.4 \\
74.8 \\
0.8 \\
4.0\end{array}$ & $\begin{array}{l}19 \\
152 \\
79 \\
0\end{array}$ & $\begin{array}{l}7.6 \\
60.8 \\
31.6 \\
0\end{array}$ \\
\hline $\begin{array}{l}\text { Water } \\
\text { storage } \\
\text { facility }\end{array}$ & $\begin{array}{l}\text { Clay pots } \\
\text { Rubber tanks } \\
\text { Open basins } \\
\text { Closed containers }\end{array}$ & $\begin{array}{l}30 \\
0 \\
17 \\
203\end{array}$ & $\begin{array}{l}12.0 \\
0 \\
6.8 \\
81.2 \\
\end{array}$ & $\begin{array}{l}30 \\
111 \\
51 \\
58\end{array}$ & $\begin{array}{l}12.0 \\
44.4 \\
20.4 \\
23.2\end{array}$ \\
\hline $\begin{array}{l}\text { Toilet } \\
\text { facility }\end{array}$ & $\begin{array}{l}\text { Water closet } \\
\text { Pit latrine } \\
\text { Bucket/pail } \\
\text { Bush/bare ground }\end{array}$ & $\begin{array}{l}- \\
104 \\
10 \\
136\end{array}$ & $\begin{array}{l}- \\
41.6 \\
4.0 \\
54.4\end{array}$ & $\begin{array}{l}133 \\
42 \\
- \\
75\end{array}$ & $\begin{array}{l}53.2 \\
16.8 \\
- \\
30.0\end{array}$ \\
\hline $\begin{array}{l}\text { Water } \\
\text { disposal }\end{array}$ & $\begin{array}{l}\text { Open gutter } \\
\text { Sewage system } \\
\text { Open ground }\end{array}$ & $\begin{array}{l}129 \\
11 \\
110\end{array}$ & $\begin{array}{l}51.8 \\
4.4 \\
44.0\end{array}$ & $\begin{array}{l}182 \\
49 \\
19\end{array}$ & $\begin{array}{l}72.8 \\
19.8 \\
7.6\end{array}$ \\
\hline $\begin{array}{l}\text { Drainage } \\
\text { sanitation }\end{array}$ & $\begin{array}{l}\text { Daily } \\
\text { Weekly } \\
\text { Monthly } \\
\text { Rarely } \\
\text { Not sure } \\
\text { Not at all }\end{array}$ & $\begin{array}{l}28 \\
100 \\
10 \\
28 \\
52 \\
32\end{array}$ & $\begin{array}{l}11.2 \\
40.0 \\
4.0 \\
11.2 \\
20.8 \\
12.8\end{array}$ & $\begin{array}{l}64 \\
128 \\
38 \\
- \\
- \\
20\end{array}$ & $\begin{array}{l}25.6 \\
51.2 \\
15.2 \\
- \\
- \\
8.0\end{array}$ \\
\hline $\begin{array}{l}\text { Refuse bin } \\
\text { system }\end{array}$ & $\begin{array}{l}\text { Covered bin } \\
\text { Backyard } \\
\text { Public ground } \\
\text { Regular refuse } \\
\text { collector } \\
\text { Public incinerator }\end{array}$ & $\begin{array}{l}0 \\
130 \\
100 \\
- \\
20\end{array}$ & $\begin{array}{l}0.0 \\
52.0 \\
40.0 \\
- \\
8.0\end{array}$ & $\begin{array}{l}83 \\
70 \\
19 \\
78\end{array}$ & $\begin{array}{l}33.2 \\
28.0 \\
7.6 \\
31.2 \\
-\end{array}$ \\
\hline
\end{tabular}

\section{Prevalence and treatment of malaria}

The experience of malaria episode in the previous 2 weeks before the survey was shared by more than half of the respondents in both locations. In addition, malaria was reported more in the urban area $(n=148 ; 59.2 \%)$ than the rural area $(\mathrm{n}=141 ; 56.4 \%)$. Malaria episodes within the last 3 months preceding the survey revealed that respondents had a range of 1 to 5 episodes of malaria in both locations. Many respondents in the rural $(n=105 ; 42.0 \%)$ and urban $(n=72$; $28.8 \%$ ) areas reportedly had one episode of malaria. Four and five episodes were reported by $72(28.8 \%)$ and $32(12.8 \%)$ respondents in the rural area than the $21(8.4 \%)$ and two $(0.8 \%)$ respondents in the urban area respectively. Also, two and three episodes were reported by $30(12.0 \%)$ and 48 (19.2\%) 
respondents respectively in the urban locations, while only nine (3.6\%) of the rural respondents reported two episodes of malaria. Only a few in urban area $(\mathrm{n}=77 ; 30.8 \%)$ than rural area $(\mathrm{n}=32 ; 12.8 \%)$ reported zero malaria episode in the last three months preceding the survey. Information on the possibility of preventing and treating malaria as well as the vulnerability of pregnant women to malaria was obtained from the respondents. All respondents in the urban location approved that malaria can be treated and that it was dangerous for women to have malaria during pregnancy. In the rural location, $17(6.8 \%)$ and seven $(2.8 \%)$ respondents were opposed to the possibility of malaria treatment and the risks it posed for pregnant women. In addition, $27(10.8 \%)$ and 20 $(8.0 \%)$ respondents in rural and urban locations respectfully did not believe that malaria is preventable.

Information placement and quality of advertisement for antimalaria product Table 3 clearly presents data on the types of information that the respondents commonly received from advertisements of anti-malaria products. A large majority reportedly received information about causes of malaria (rural $=93.2 \%$; urban $=84.0 \%$ ), and prevention of malaria (rural 93.2\%; urban $92.0 \%$ ). Other information included appropriate dosage, effectiveness of antimalaria products, drug reaction and side effects and cost of antimalaria products, as shown in Table 3.

Table 3: Types of Information Received From Anti-malaria Advertisements

\begin{tabular}{|l|l|l|l|l|}
\hline \multirow{2}{*}{ TYPES OF INFORMATION } & \multicolumn{3}{|l|}{ RURAL AREA } & \multicolumn{2}{l|}{ URBAN AREA } \\
\cline { 2 - 5 } & FREQ & \% & FREQ & \% \\
\hline Cause of malaria & 243 & 97.2 & 210 & 84.0 \\
\hline Prevention of malaria & 233 & 93.2 & 230 & 92.0 \\
\hline Effectiveness of anti-malaria products & 10 & 4.0 & 80 & 32.0 \\
\hline $\begin{array}{l}\text { Side effects and drug reaction of anti- } \\
\text { malaria product }\end{array}$ & 10 & 4.0 & 31 & 12.4 \\
\hline Cost of anti-malaria products & - & - & 11 & 4.4 \\
\hline Appropriate dosage & 80 & 32.0 & 89 & 35.6 \\
\hline
\end{tabular}

Table 4 presents the opinion of the respondents on the quality of antimalaria drugs and products, and the quality of information that respondents received through different sources. Responses were rated as SA=Strongly Agreed, $\mathrm{A}=$ Agreed, $\mathrm{U}=$ Undecided, $\mathrm{D}=$ Disagreed, and $\mathrm{SD}=\mathrm{Strongly}$ Disagreed. Values were awarded to the options as $\mathrm{SA}=5, \mathrm{~A}=4, \mathrm{U}=3, \mathrm{D}=2$, and $\mathrm{SD}=1$ giving rise to $5+4+3+2+1=15$. The mean score was $3(15 / 5=3)$; hence, by merging the score, analysis indicated that any mean score 3 and above connotes that respondents "agreed" to the variable statement, while any mean score below 3 indicated that respondents "disagreed" to the variable statement. The Remarks shown in table 4 reveals the overall opinion of the respondents (either they agreed or disagreed to the statement). Clearly, Table 4 reveals that respondents in the 
rural and urban areas agreed that: the language used in advertisement of antimalaria drugs and products was appropriate and the information they received was clear to them; the duration was neither too long nor too short. Also, they revealed that advertisement of anti-malaria drugs and products was audiencefriendly. Furthermore, respondents opined that advertisements should contain indications that they have been approved by the Federal Government of Nigeria; have a label that bear national logo; include statistics on prevalence of malaria; and billboards should contain photographs reflecting the menace of malaria.

Table 4: Respondents' Opinion about Advertisement of antimalaria drugs and products

\begin{tabular}{|l|l|l|l|l|l|l|l|}
\hline \multicolumn{1}{|c|}{ RURAL } & SA & A & U & D & SD & $\begin{array}{l}\text { Mean } \\
\text { score }\end{array}$ & Remarks \\
\hline Appropriate Language & 233 & - & - & 10 & - & 4.9 & Agreed \\
\hline Clarity of information & 99 & 13 & - & 34 & - & 4.7 & Agreed \\
\hline Long duration of time & 30 & 59 & - & 20 & 134 & 2.3 & Disagreed \\
\hline Short time duration & 19 & 12 & 40 & 59 & 120 & 2.0 & Disagreed \\
\hline $\begin{array}{l}\text { The advertisement are } \\
\text { audience friendly }\end{array}$ & 139 & 41 & 23 & 16 & 31 & 3.9 & Agreed \\
\hline $\begin{array}{l}\text { Government approval of anti- } \\
\text { malaria product } \\
\text { advertisement }\end{array}$ & 212 & 21 & 10 & 7 & - & 4.8 & Agreed \\
\hline $\begin{array}{l}\text { Mounting of Billboard to } \\
\text { present pictures reflecting the } \\
\text { menace of malaria }\end{array}$ & 151 & 52 & 30 & - & 10 & 4.4 & Agreed \\
\hline $\begin{array}{l}\text { Advertisement of anti- } \\
\text { malaria product should have } \\
\text { a label that bear the national } \\
\text { logo }\end{array}$ & 106 & 31 & 40 & 32 & 41 & 3.5 & Agreed \\
\hline $\begin{array}{l}\text { Advertisement of anti- } \\
\text { malaria product should } \\
\text { contain statistics on malaria }\end{array}$ & 154 & 22 & 7 & 56 & 11 & 4.0 & Agreed \\
\hline \multicolumn{1}{c|}{ URBAN } & SA & A & U & D & SD & $\begin{array}{l}\text { Mean } \\
\text { score }\end{array}$ & Remarks \\
\hline Appropriate Language & 111 & 108 & 11 & 20 & - & 4.2 & Agreed \\
\hline Clarity of information & 70 & 149 & 17 & - & - & 3.0 & Agreed \\
\hline Long duration of time & 11 & 11 & - & 75 & 129 & 1.7 & Disagreed \\
\hline Short time duration. & 31 & 39 & 82 & - & 98 & 2.6 & Disagreed \\
\hline $\begin{array}{l}\text { The advertisement are } \\
\text { audience friendly }\end{array}$ & 58 & 109 & 83 & - & - & 3.9 & Agreed \\
\hline $\begin{array}{l}\text { Government approval of anti- } \\
\text { malaria product } \\
\text { advertisement }\end{array}$ & 158 & 70 & 22 & - & - & 4.5 & Agreed \\
\hline
\end{tabular}




\begin{tabular}{|l|l|l|l|l|l|l|l|}
\hline $\begin{array}{l}\text { Mounting of Billboard to } \\
\text { present pictures reflecting the } \\
\text { menace of malaria }\end{array}$ & 189 & 22 & 39 & - & - & 4.6 & Agreed \\
\hline $\begin{array}{l}\text { Advertisement of anti- } \\
\text { malaria product should have } \\
\text { a label }\end{array}$ & 159 & 20 & 10 & 19 & 40 & 4.0 & Agreed \\
\hline $\begin{array}{l}\text { Advertisement of anti- } \\
\text { malaria product should } \\
\text { contain statistics on malaria }\end{array}$ & 121 & 31 & 20 & - & 78 & 3.8 & Agreed \\
\hline
\end{tabular}

Accessibility and Preference for Medium of Advertising Antimalaria

Table 5 shows findings on extent of accessibility and possession of medium of information about antimalaria by location. It also provides information about respondents' preferred medium of receiving advertisement, preferred forms of advertisement and preferred role models in antimalarial advertisement. Radio set was the most accessible tool of information as indicated by $333(66.6 \%)$ respondents from rural and urban locations. Radio was also an acceptable medium to large majority (81.2\%) of respondents in the rural area. Television as a medium of information was also reportedly accessible in both locations but exponentially accessible in urban $(n=100)$ than in rural $(n=5)$ locations. Internet facilities and social media usage were also accessible in the urban area, while adoption of town criers was reportedly a norm in the rural location as shown in Table 5.

Respondents clarified that their indication of accessibility was based on mobility ( $\mathrm{n}=224 ; 44.8 \%$ in both locations) and affordability $(\mathrm{n}=167 ; 33.4 \%$ in both locations) of each medium of information. Other responses included the perceived portability of the medium and constant power supply. There is no gainsaying that respondents' expectation of a medium's degree of mobility was acceptable reason without much significant difference in the rural and urban locations, but that it was more alluded to as a determinant of "access" than other factors in both locations. When respondents were probed for their most preferred medium for receiving advertisements, radio set was also reported by the large majority (70.2\%) in both locations and was preferred by $97.2 \%$ of the rural respondents. Preference for the medium of receiving advertisement was reportedly hinged on their perception that it is affordable $(50.2 \%)$, more informative $(20.0 \%)$, draws more attention $(18.0 \%)$ and mobile $(11.8 \%)$ as shown in both location.

The forms of advertisement that the medium utilised in promoting antimalaria was also examined. The various forms examined in this study include movable billboards screen at key location junctions; pictures; drama; music; speech; and jingles. In both locations, almost half $(49.4 \%)$ of the respondents preferred advert in form of speech; while more than a quarter $(26.2 \%)$ of the respondents in both locations preferred advert in form of drama. A sharp difference however exists in the level of preference by location. This may be explained in terms of available medium by location. For instance, 
advert in form of speech could be preferred since it could be disseminated through radio (the most preferred medium of advert to rural dwellers) as indicated by $86.4 \%$ respondents in the rural areas. Whereas, advert in form of drama may be enjoyed and preferred more on television set as common to urban $(44.0 \%)$ respondents.

Table 5 also indicates that the choice of the most preferred form of advertisement gained ground for being more informative/educative as reported by a large majority $(73.6 \%)$ of the respondents in the rural areas, and nearly half $(47.6 \%)$ of the total respondents in the urban areas. The form of advertisement was also considered self-explanatory by about a quarter of the total respondents in both locations. Table 5 also reveals the category of experts (role models) that respondents preferred in promoting advertisement of antimalaria drugs and products. The large majority (92.0\%) of the respondents in rural area preferred popular health workers, while only $4.0 \%$ each (rural and urban) preferred university scholars and entertainment stars. As against the preference rates in rural areas, about half $(\mathrm{n}=118,47.2 \%)$ of urban respondents preferred entertainment stars; followed by $44.8 \%$ who preferred popular health workers and $8.0 \%$ who preferred university scholars.

Table 5: Respondents' most accessible medium of information

\begin{tabular}{|l|l|l|l|}
\hline $\begin{array}{l}\text { Media types and } \\
\text { features }\end{array}$ & $\begin{array}{l}\text { Rural area } \\
\text { (N=250) }\end{array}$ & $\begin{array}{l}\text { Urban area } \\
\text { (N=250) }\end{array}$ & $\begin{array}{l}\text { Total } \\
\text { (N=500) }\end{array}$ \\
\cline { 2 - 3 } & Frequency (\%) & Frequency (\%) & \\
\hline Television & $5(2.0 \%)$ & $100(40.0 \%)$ & $105(21 \%)$ \\
\hline Radio & $203(81.2 \%)$ & $130(52.0 \%)$ & $333(66.6 \%)$ \\
\hline Internet & - & $10(4.0 \%)$ & $10(2.0 \%)$ \\
\hline Social media & - & $10(4.0 \%)$ & $10(2.0 \%)$ \\
\hline Town criers & $42(16.8 \%)$ & - & $42(8.4 \%)$ \\
\hline Reasons for the Most Accessible Medium of Information \\
\hline Affordability & $58(23.2 \%)$ & $109(43.6 \%)$ & $167(33.4 \%)$ \\
\hline $\begin{array}{l}\text { Constant electricity } \\
\text { supply }\end{array}$ & - & $20(8.0 \%)$ & $20(4.0 \%)$ \\
\hline Mobility & $113(45.2 \%)$ & $111(44.4 \%)$ & $224(44.8 \%)$ \\
\hline Portability & $79(31.6 \%)$ & $10(4.0 \%)$ & $89(17.4 \%)$ \\
\hline Respondents' Most Preferred Medium of Advertisement \\
\hline Billboard & - & $39(15.6 \%)$ & $39(7.8 \%)$ \\
\hline Television & - & $92(36.8 \%)$ & $92(18.4 \%)$ \\
\hline Radio & $243(97.2 \%)$ & $108(43.2 \%)$ & $351(70.0 \%)$ \\
\hline Newspaper & - & $11(4.4 \%)$ & $11(2.2 \%)$ \\
\hline Town criers & $7(2.8 \%)$ & - & $7(1.4 \%)$ \\
\hline Respondents' Reasons for Most Preferred Medium of Advertisement \\
\hline Affordability & $161(64.4 \%)$ & $90(36.0 \%)$ & $251(50.2 \%)$ \\
\hline Mobility & $39(15.6 \%)$ & $20(8.0 \%)$ & $59(11.8 \%)$ \\
\hline More informative & $10(4.0 \%)$ & $90(36.0 \%)$ & $100(20.0 \%)$ \\
\hline It draws attention better & $40(16.0 \%)$ & $50(20.0 \%)$ & $90(18.0 \%)$ \\
\hline
\end{tabular}




\begin{tabular}{|l|l|l|l|}
\hline \multicolumn{4}{|l|}{ Respondents' Most Preferred Form of Advertisement } \\
\hline Movable Billboards & $6(2.4 \%)$ & $20(8.0 \%)$ & $26(5.2 \%)$ \\
\hline Pictorial & $7(2.8 \%)$ & $20(8.0 \%)$ & $27(5.4 \%)$ \\
\hline Drama & $21(8.4 \%)$ & $110(44.0 \%)$ & $131(26.2 \%)$ \\
\hline Music & - & $39(15.6 \%)$ & $39(7.8 \%)$ \\
\hline Speech & $216(86.4 \%)$ & $31(12.6 \%)$ & $247(49.4 \%)$ \\
\hline Jingles & - & $30(12.0 \%)$ & $30(6.0 \%)$ \\
\hline Respondents' Reasons for Choice of Most Preferred Form of Advertisement \\
\hline Self-explanatory & $66(26.4 \%)$ & $61(24.4 \%)$ & $127(25.4 \%)$ \\
\hline Interesting & - & $51(20.4 \%)$ & $51(10.2 \%)$ \\
\hline $\begin{array}{l}\text { More informative/ } \\
\text { educative }\end{array}$ & $184(73.6 \%$ & $119(47.6 \%)$ & $303(60.6 \%)$ \\
\hline It draws more attention & - & $19(7.6 \%)$ & $19(3.8 \%)$ \\
\hline Respondents' Most Preferred Role Model in Promoting Antimalaria Products \\
\hline Entertainment stars & $10(4.0 \%)$ & $118(47.2 \%)$ & $128(25.6 \%)$ \\
\hline University scholars & $10(4.0 \%)$ & $20(8.0 \%)$ & $30(6.0 \%)$ \\
\hline Popular health workers & $230(92.0 \%)$ & $112(44.8 \%)$ & $342(68.4 \%)$ \\
\hline
\end{tabular}

The narratives from Patent Medicine Vendors (PMVs) compliment survey data in different ways. Results from focused observational studies (Akuse, Eseigbe, Ahmed and Brieger, 2010; Brieger, Osamor, Salami, Oladepo and Otusanya, 2004) and scoping studies (Goodman, Brieger, Unwin, Mills, Meek and Greer, 2007) had confirmed PMVs as first possible point of contact not only for drugs and health products, but a major source of advice and guidance on health (Brieger et al., 2004; Salami and Brieger, 2006) to the people in rural and urban areas. The PMVs in this study whose educational status ranged from "no formal education" to "SSCE" did not only sell drugs and other health products to consumers in rural areas, they were also consulted for health related information. Narratives from the PMVs revealed a low level of exposure to technology in the rural community, though the level of social interaction and solidarity is high. However, people take the advantage of local resources to disseminate information in the community. One PMV estimated the size of the community where they operate and affirmed that the best way to promote antimalarial drugs was to organise a community meeting where direct face-toface information is passed to the people. The PMV noted that:

As this is a small community, one functional way to go about creating awareness on malaria here is to gather people with the consent of the community head (Baale). Then the people have to be addressed using 'soft words' as they are taught the best ways of preventing and treating malaria. Through the town hall meeting, people will be advised to clear their environment in order to reduce the risk of getting malaria. At the meeting, people will be told when to listen to the radio for more information. (KII/Egbeda/50yrs) 
House-to-house approach was also emphasised as a useful first level approach in information dissemination in rural area. Preference for word of mouth in the local language that people understand was shared by a PMV:

House-to-house campaign will go a long way to help. It is the most effective for passing information in this locality. After the house-to-house campaign, the professionals can stay at the health centre for the people who will be visiting the hospital. (PMV/Egbeda/32yrs)

A narrative that compared the value of advertisement disseminated through 'handbill or fliers' with one that was based on 'word of mouth' indicated that dissemination through 'word of mouth' requires no much expertise, yet it recorded a high success rate during a cholera outbreak in the community: Usually when advertisements are disseminated via handbills, posters or fliers, people do not bother to read them and so they have no effect. Of recent, there was cholera outbreak here and it took at least 11 lives, then a group of health practitioners came here to lecture people from house-to-house, and it really made an impact here. (PMV/Egbeda/38yrs)

While respondents in the rural areas preferred advertisement of anti-malaria drugs and products to be on radio, from health workers, during rallies, in town hall meetings, and house-to-house campaigns, the narratives from the urban pharmacists revealed a contrasting view from what their PMV counterparts in the rural area said. For the urban PMVs, health information within the busy shores of an urban system should take the advantage of modern technology to reach the people. The PMVs placed particular emphasis on the use of radio set and television in advertising antimalarial drugs and products to improve the health behaviour of the people. This position was buttressed in an interview session with a PMV who said:

Television and radio advertisements are good for an area like this. For example, there are some TV adverts with nice drama and jingles that people cannot forget. Like that Lonart advert where malaria was taken to court 'is a nice one' and even if you bring a child here, the person can tell you about the advert. (Pharm/Ibadan north/38yrs)

Radio sets was reported as more preferable by another PMV. Loss of trust in programmes that TV features most times actually discouraged its patronage in recent times as pointed out by a PMV:

I think radio advertisement is the best. This is because most people do not have the time to start watching television. Also, most people have lost interest in television because of the nonsense that are often projected on TV, like girls going naked and boys sagging. (Ibadan north/45yrs) 
Clearly, the most preferred source of advertisement in the urban area is radio. A considerable number of people preferred television advertisement but were discouraged by factors such as immoral scenes, irregular supply of electricity and busy schedule.

\section{Discussion}

Malaria episodes are higher in rural locations than in urban in this study, even though both locations provided high rates of malaria experiences. Residents in this study had limited access to safe source of water. Respondents indicated well water as their main source from where they get water in both rural and urban locations. Most respondents in the rural (74.8\%) and the urban (60.8\%) areas in this study depended on Well; as their main source of water supply. Wells, especially those without cover, provide a conducive breeding ground for mosquitoes that cause malaria. Studies have established the fact that the absence of satisfactory water supply in households has implication for malaria occurrence (Joseph, 2012). Only $20.0 \%$ of the respondents in the rural area and $7.6 \%$ of the respondents in the urban area had access to tap water, while access to borehole was available to very few $(0.8 \%)$ respondents in the rural area and $32.0 \%$ in the urban area.

Poor toilet facilities, poor water disposal and improper refuse disposal facilities were reported in this study. All these are attributes of behaviours and attitude that influence mosquito breeding. For instance, poor toilet, amongst other poor housing facilities, provides less protection against mosquito bite (Prathiba, 2012). Also, more than average of the respondents in both the rural $(51.8 \%)$ and the urban $(72.8 \%)$ areas disposed water into open gutters, which on average was sanitised weekly; such attitude and practice could promote conducive breeding-space and ready residuals for mosquito (Adeleke, Mafiana, Idowu, Adekunle and Samwobo, 2008), thus have an implication for the occurrence of malaria. This study also shows poor hygiene, sanitation and waste collection practices among the respondents. These are key determinants of malaria transmission. The more households dispose of waste properly, the lower the risk of liquid waste collecting in pools of stagnant water and forming vector breeding sites (Prathiba, 2012). In the rural area, more than half of the total respondents reported that they disposed their refuse at their back yard, while $40.0 \%$ reportedly dumped their refuse on public grounds. In the urban area, only $33.2 \%$ had covered bins in their house and about $31.0 \%$ had access to regular refuse collectors; others disposed their refuse either in an open space or on public grounds.

Information pertaining to side effects of antimalaria products, drug reactions and cost of antimalaria products were rarely received from advertisement of malaria products in both study locations. Clearly, advertisement of antimalaria products disproportionately focus on benefits of using antimalaria products while neglecting the risks involved in using such products. Such incomplete information, which shows the lack of fair balance between the benefits and risks of using a particular health-related product, is 
inappropriate in health communication (Avery, Eisenberg and Simon, 2012; Adams, 2016). Previous studies (Frousch, Krueger, Hornik, Cronholm and Barg, 2007; Macias, Pashupati and Lewis, 2007; Avery, Eisenberg and Simon, 2012; Faerber and Kreling, 2014) that focused the content of advertisement of direct-to-consumer drugs, observed that most advertisements tend to pay less attention to drug risks or negative reactions of using drugs, but emphasized the benefits of using the drugs. Adams (2016) opined that most advertisement avoid information on drug risks because of their potential for making advertisements more lengthy and subsequent increase in the cost incurred on advertisement.

Respondents in this study emphasized the issues of quality in advertisement; standard practice in advertisement; and use of appropriate technology in advertisement as ways of best practice. For instance, the use of appropriate language, clear information, and adequate timing of advertisement were emphasized as factors that influenced the quality of advertisement of antimalaria products in both rural and urban areas. Also, the need for the rate of malaria episode to be included on the advertisement was expected to give a clear picture of malaria prevalence and incidence rates, while putting billboards with picture of someone that has malaria at key junctions in rural and urban areas, was expectedly necessary to depict the cause, mode of transmission and consequence of malaria. The use of pictures in advertisements tends to be more effective than written words as it; attracts attention of the audience towards the message being passed across, enables easy comprehension, help people recall information easily and provides cue to action (Nkana, 2015). Graphic visuals, presenting the severity of a health issue, is noted an effective strategy used in health communication especially in improving appropriate health behaviour (Adams, 2016). This strategy tends to introduce fear appeals to the audience and persuade individuals towards appropriate preventive and curative actions. Studies on the effects of graphic anti-smoking and anti-drinking advertisements revealed that people who come in contact with such advertisements were more likely to avoid smoking and drinking (Kees, Burton, Andrews and Kozup, 2010; Yu, Ahern, Connoly-Ahern and Shen, 2010; Andrews, Netemeyer, Keeys and Burton, 2014). Adoption of such practice in the advertisement of antimalarial drugs and products could produce useful results in the control of malaria.

The findings in this study show radio as the most preferred and most accessible medium of getting information pertaining to malaria in both rural and urban areas in Ibadan. This corroborates the finding by Luyiga (2013) from a study on the knowledge, attitude and practices of malaria prevention and control in Uganda, where majority $(62.9 \%)$ of the respondents got their information from radio. This is also in line with the findings of Ndifreke, Abraham and Aniekan (2012), where it was established that greater percentage of the youths in Calabar get information about malaria on radio.

Attention should be paid to differences in the acceptable means of information dissemination in rural and urban locations as shown in this study. 
For instance, asides radio, urban dwellers prefer advertisement shown on TV, as most of them either possess one, or can access it. The rural dwellers on the other hand prefer rallies, community meetings and house-to-house visitations. These positions were also maintained in Luyiga's (2013) study where rural dwellers reportedly got information from health centre $(23.6 \%)$ and the village health team members $(17.9 \%)$; for these media allowed speeches and face-toface interaction, and opportunity to make enquiries when they were not clear. Luyiga (2013) also reported that urban dwellers preferred advertisements and communication programmes designed in form of drama and music, for reasons that information that come through these media is easy to remember, interesting and self-explanatory.

This study further discovered a difference in the preferred forms of advertisements of antimalaria products in rural and urban areas. A very large majority $(86.4 \%)$ of the respondents in the rural areas expressed their preference for advertisements in form of speeches. This is explained in terms of the nature of rural environments where information is mostly disseminated using folk-media such as house-to-house visitations, town criers and town hall meetings (Salami and Onuegbu, 2016). On the other hand, most urban dwellers prefer advertisement in form of drama on TV sets and find it more informative and educative. This is also reflective of the nature of urban centers where most people either own or can access TV sets (Salami and Onuegbu, 2016).

The relevance of role model in health communication is expressed in this study. Preference for role model is influenced by the location in this study; the urban dwellers mostly preferred popular stars in entertainment while the rural dwellers mostly preferred popular health workers in promoting advertisement of antimalaria drugs and products. Both categories of people are perceived as celebrities to the public. It was noted that the credibility or attractiveness of popular role models exert much influence with their presence in advertisements (Zipporah and Mberia, 2014). Similar studies on the influence of the presence of celebrities in advertisements of products found that, consumers are more likely to purchase products advertised by celebrities than other products advertised by unknown models (Joshi and Ahluwalia, 2008; Matrade, 2005; Lalitha and Kumar, 2010).

\section{Conclusion}

This study shows that information on side effect or possible reactions of antimalaria drugs and treatment of possible side effects are less available to clients. Rather, common messages are centred on causes, prevention and sometimes on appropriate dosage of drugs. This suggests the need for manufacturers and distributors of anti-malaria products (ACTs, ITNs and insecticides) to design advertisement in such a way that it includes clients' needs on antimalarial treatment information. No dissatisfaction was reported from both rural and urban respondents on the language used in advertisement of anti-malaria products, clarity of the information received from advertisement of anti-malaria products, and the appropriate time and duration of time schedule. However, the 
respondents opined that advertisements should also lay more emphasis on government approval through drug regulatory bodies, as proof of effectiveness of the drugs. Also, billboards reflecting the menace of malaria should be mounted at strategic points in the rural areas.

The findings of the study reveal that in passing information across to people on malaria prevention and treatment, the location of the people must be considered. This is important to ensure that the most accessible and most preferable means of communication is utilised in the dissemination of information on malaria treatment and prevention in Nigeria.

\section{References}

Adams, C. (2016) Fair Balance and Adequate Provision in Direct-to-Consumer Prescription Drug Online Banner Advertisements: A content Analysis. Journal of Medical Internet Research, 18(2): 1-14.

Adeleke, M.A., Mafiana, C.F., Idowu, A.B., Adekunle, M.F. and Samwobo S.O. (2008) Mosquito larval habitats and public health implications in Abeokuta, Ogun state, Nigeria. Tanzania journal of Health Research, 10(2): 103-107.

Akinleye, S.O. (2007) Rural Infrastructure and Household Health Status in Yewa North LGA, Ogun state. In Aihonsu J.O.Y., Olubanjo O.O., Akileye S.O. and Okuneye, P.A. (eds.). Proceedings on the Farm Management Association of Nigeria Conference, pp. 295-299.

Akuse, R.M., Eseigbe, E.E., Ahmed, A. and Brieger, W.R. (2010) Patent Medicine Sellers: How Can They Help Control Childhood Malaria? Malar Res Treat. 2010: 470754.

Andrews, J.C., Netemeyer, R.G., Kees, J. and Burton, S. (2014) How Graphic Visual Health Warnings Affect Young Smokers' Thoughts of Quitting. Journal of Marketing Research, 51(2): 165-183.

Avery, R.J., Eisenberg, M. and Simon, K.I. (2012) Fair Balance in Direct-toConsumer Antidepressant Print and Television Advertising, 1995-2007. Journal of Health Communication, 17(3): 250-277.

Brieger, W.R., Osamor, P.E., Salami, K.K., Oladepo, O. and Otusanya, S.A. (2004) Interactions between Patent Medicine Vendors and Customers in Urban and Rural Nigeria. Health Policy and Planning, 19(3): 177-182.

Faerber, A.E. and Kreling, D.H. (2012) Now You See It. Now You Don't: Fair Balance and Adequate Provision in Advertisements for Drugs Before and After the Switch from Prescription to Over-the-Counter. Health Communication, 27(1): 66-74.

Frousch, D.L., Krueger, P.M. and Hornik, R.C. Croholm, P.F. and Barg, F.K. (2007) Creating Demand for Prescription Drugs: A Content Analysis of Television Direct-to-Consumer Advertising. Annals of Family Medicine, 5(1): 6-13.

Goodman, C., Brieger, W., Unwin, A., Mills, A., Meek, S. and Greer, G. (2007) Medicine Sellers and Malaria Treatment in Sub-Saharan Africa: 
What do they do and how can their practice be improved? Am J Trop Med Hyg.; 77: 203-18.

Joseph, M. (2012) Contributory Factors to the Spread of HIV/AIDs and its Impacts in Sub-Saharan African Countries. European Scientific Journal, 8(14): 144-156.

Luyiga, F.M. (2013) Knowledge, attitude and practices on malaria prevention and control in Uganda. Communication for development foundation Uganda (CDFU). Retrieved online via http://www.cdc.gov/malaria/ malariaworldwide/index.html.

Kees, J., Burton, S., Andrews, J.C. and Kozup, J. (2010) Understanding How Graphic Pictorial Warnings Work on Cigarette Packaging. Journal Public Policy Mark, 29(2): 265-276.

Marcias, W., Pashupati, K. and Lewis, L.S. (2007) A wonderful Life of Diarrhea and Dry Mouth? Policy Issues of Direct-to-Consumer Drug Advertising on Television. Health Communication, 22(3): 241-252.

Ndifreke, E.U., Abraham, N.G. and Aniekan, J.E. (2013) Malaria: Knowledge and prevention practices among school adolescents in a coastal community in Calabar, Nigeria. African Journal of Primary Healthcare and Family Medicine. 2(1): 1-4.

Nigeria Malaria Fact Sheet (2011).

Nigeria Malaria Indicator Survey Final Report (2012) Calverton, Maryland United States.

Nkana, N.S. (2015) Pictorial Impact of Television Political Advertising on Voters in a Multi-Cultural Environment. International Journal of Asian Social Science, 5(4): 220-232.

Oladepo, O., Tona, G.O., Oshiname, F.O. and Titiloye, M.A. (2012) Malaria Knowledge and Agricultural Practices that Promote Mosquito Breeding in Two Rural Farming Communities in Oyo State, Nigeria. Malaria Journal, 9(91). Doi: 10. 1186/1475-2875-9-91.

Pechmann, C. and Jesse, R.C. (2016) The Effects of Advertising and Other Marketing Communications on Health-related Consumer Behaviors. Current Opinion in Psychology, 10: 44-49.

Prathibiba, M., De Silva and John M.M. (2012) Factors Contributing to Urban Malaria Transmission in Sub-Saharan Africa: a systematic review. Journal of tropical medicine. Doi: 10.1155/2012/819563

Salami, K.K. and Brieger, W.R. (2006) Consumer Response and Satisfaction with Prepackaged Antimalarial Drugs for Children in Aba, Nigeria. International Quarterly of Community Health Education. 24(3): 213-227.

Salami, K.K. and Onuegbu, C.M. (2016) Location and Media Dynamics in Information Sharing in Ibadan, Southwestern Nigeria. African Journal for Psychological and Social Sciences Issues, 19(2): 28-41.

Usman, A. and Adebayo, M. (2011) Socio-Economic Impact of Malaria Epidemics on Households in Nigeria: Micro Evidence from Kwara State. International Journal of Asian Social Sciences, 1(5): 188-196. 
World Health Organization (2010) Guidelines for the treatment of malaria, $2^{\text {nd }}$ Edition Geneva. Pp.19-21.

$\mathrm{Yu}$, N., Ahern, L.A., Connolly-Ahern, C. and Shen, F. (2010) Communicating the Risks of Fetal Alcohol Spectrum Disorder: Effects of Message Framing and Exemplification. Health Communication, 25(8): 692-699.

Zipporah, M.M. and Mberia, H.K. (2014) The Effects of Celebrity Endorsement in Advertisements. 2014. International Journal of Academic Research in Economics and Management Sciences, 3(5): 178-188. 